https://doi.org/10.48009/1_iis_2006_193-198

\title{
QFD APPLICATION TO IMPROVE MANAGEMENT EDUCATION AT KIMEP
}

\author{
Shamsuddin Ahmed, Kazakhstan Institute of Management, Economics and Strategic Research, \\ Dr_Shamsuddin_Ahmed@Yahoo.Com
}

\begin{abstract}
This paper demonstrates how an institution of higher education, explicitly Kazakhstan Institute of Economics, Management and Strategic Research, KIMEP, can apply the Quality Function Deployment (QFD) to translate Voices of Customer (VoC) into program requirements. The student needs and requirements were identified to develop the foundation in delivering quality curriculum and services in higher education. The House of Quality (HoQ) illustrates the transformation process from student requirements to instructional development. For QFD analysis, a survey with Bang College of Business $(B C B)$ students having interest in discipline specific courses was structured. The QFD data analysis suggests that the curriculum needs restructuring. The number of tutorial sessions needs more time; exam needs restructuring, while the weight of the quizzes should be increased. The technical resources are necessary to deliver courses effectively. Most of the students in discipline felt the need of qualified instructors with pedagogical skills and business experience.
\end{abstract}

Keywords: QFD, House of Quality, Business Education, TQM

\section{INTRODUCTION}

The changing economic environment of Kazakhstan in the midst of globalization process is having an impact not only on the business entities, but also on academic institutions. If, for business entities, delivering high quality products is essential, then competitiveness is the important contributing factor; but there is a slightly different situation with academic institutions. State universities are traditionally funded or supported by government and the competition for outstanding students as well scarce resources is less intense there. At the private institutions the situation is different. The competition for funding, resources and good students is very tough at private universities. Striving for excellence in everything that a university does has become the credo of the institutions. Therefore, the institution must function efficiently and effectively in order to maintain its sustainable comparative advantage on the market. One such institution is KIMEP, which is striving for excellence in education and has been working toward achieving international institutional and program accreditation. It is currently facing tough competition from Kazakh British Technical University, which is also delivering quality educational services. Therefore, practicing total quality management (TQM) in today's competitive business education environment is indispensable at KIMEP. It is unambiguous that quality is crucial in delivering education; the question is how to deliver quality education at KIMEP.

Education is a process of converting tangible resources into intangible resources [6]. The product of education is often intangible and difficult to quantify because it is reflected in the transformation of individuals in their knowledge, their characteristics, and their behavior [2]. Higher education develops a person for creative, critical and analytical skills. Upon graduation they are able to solve problems independently and cost effectively. Higher education is not only a rigorous study process of obtaining necessary professional qualifications, but it is also an intellectual development of an individual, which will have an enduring impact on one's life. Therefore, quality education means not only adding value to students, but also to the society as a whole, since the products of an university are employed at GDP generating business entities of the country, and thus these individuals are the ones on whom the prosperity, productivity and security of the country depends [11].

Quality function deployment (QFD) is a methodology for the development of features, attributes, or functions that give a product or service high quality. It is helpful in answering the question how to deliver quality education and services based on the needs of students, society, or the voices of customers (VOC). Even though the quality principles are compatible with the values of higher education, often the culture must change to support these principles [15]. For the culture to change, the members need to shift their thinking about how work is done. Consequently, modifying teaching methods, redesigning the course structure, restructuring the faculty composition would be equivalent to revising the pedagogical qualities, manners of delivery and benchmarking the practices. 


\section{QFD Applications in Higher Education}

The QFD applications in higher education is classed into three broad categories, namely, teaching effectiveness, curriculum design, and instructional resources. Clayton [6] used QFD to provide productive quality learning. Jaraiedi and Ritz [9] applied QFD to improve advising and teaching processes at West Virginia University. Benjamin et. al, [3] designed engineering education and curricula using TQM and QFD principles. Chen and Bullington [5] reported QFD application in research and strategic planning. Ermer [7 showed the design requirements to satisfy each customer by considering faculty, students, and industry as clients. Hwarng et. al, [8] applied QFD at the National University of Singapore.

\section{QFD at KIMEP}

The house of quality model for KIMEP was built in the following way. The students studying discipline specific courses in BCB answered an initial questionnaire aimed at mapping the VOC. All individual answers were collected, summarized and evaluated. Next a focus group was asked to categorize the needs by categories, and in total 31 needs were identified, as displayed in Figure 1. These customer requirements to the course were categorized into professor-based needs, the course content requirements and the educational facility requirements.

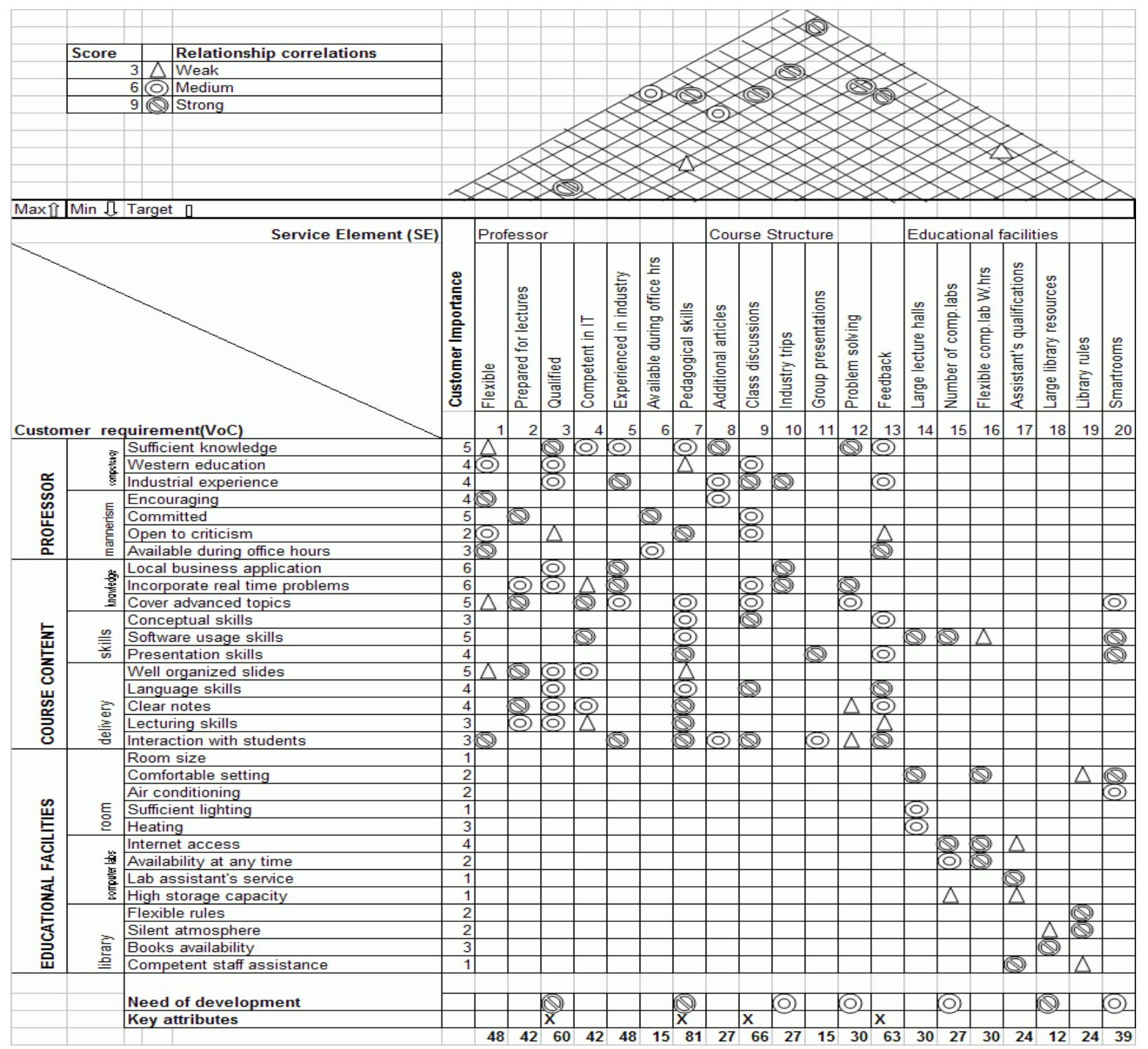

Figure 1. House of Quality 
Furthermore, the professor category was subdivided into mannerism and competency requirements. The course content category was subdivided into knowledge, skill and delivery requirements. The educational facilities requirement was subdivided into room, computer labs and library requirements. The graduating students appreciated the need of business/industry trips, application of local problems in the course and business background of the professor. The second and third year students focused more on course content, on mannerism of the instructor and on the educational facility availability. The focus groups ranked the customer importance of each of the customer requirements. In total the rankings for 31 elements add up to 100 . In next step, the correlation matrix between the VOC and service elements was developed. Three degrees of correlation were assigned: weak, medium and strong. Scores of 3, 6, and 9 were assigned to each of them accordingly. The correlation matrix was developed based on questionnaire results and on brainstorming conducted with the selected focus group of students. The prioritized needs together with course attributes were then summarized in HoQ (Figure 1). The service elements were derived from brainstorming sessions and most of them are the activities of BCB. Those attributes that need to be further developed are at the bottom of HoQ, and they are marked. The key attributes were obtained by combining the number and strengths of the relationships within each column and the code of the associated needs. The key attributes thus identified are the qualifications of the instructor's pedagogical skills, class discussions and feedback. The need for further development was identified in seven categories.

\section{RESEARCH METHODOLOGY}

To conceal the identity of the BCB target department and courses, the coded names were used in this paper. The students of JN, GJN, NC and JCN courses at the target BCB discipline were selected for questionnaire purposes. There were seventeen questions in total and some questions contained an additional subset of query. Specifically these courses were selected because different instructors of these courses have different backgrounds and experience in teaching. The factors that influenced the course delivery were a) teaching skills and knowledge of the instructor; b) effective tutorials; c) well-arranged slides; d) selfexplanatory, well documented study material. Figure 2 depicts the percentage distribution on the influence of each of the components on course delivery.

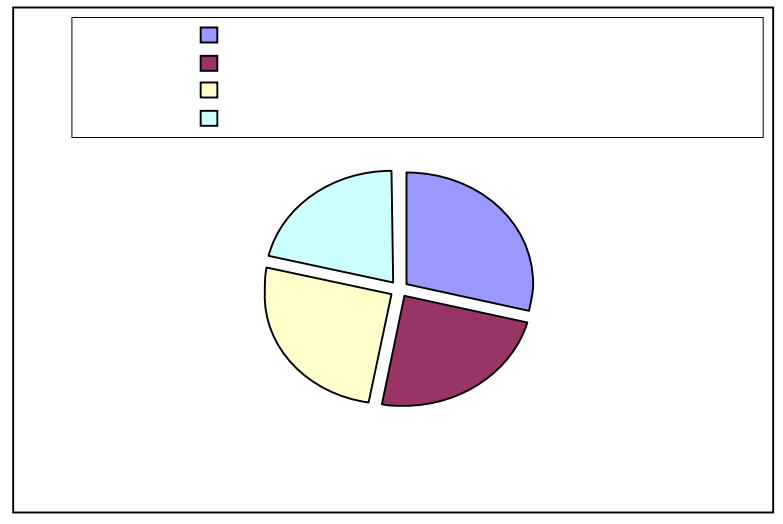

From Table 1, we see the majority of students were satisfied with the quality of education delivered to them in JN course $(66.7 \%)$, while the student ranked the NC course with low quality. The students considered the course material not equivalent to what ought to have been taught. The instructor of the NC course focused on non-discipline-specific course material to suit the interest of the instructor rather than the curriculum. The administrators of the BCB discipline department oversee the course content over the semesters. The students were greatly dissatisfied with the quality of the course delivery. To the question of whether the instructor was qualified to teach the course, 93\% agreed that the GJN course instructor was qualified.

Table 1. Summary Results

\begin{tabular}{|c|c|c|c|c|}
\hline Questions & GIN & JT & JGN & NC: \\
\hline $\begin{array}{l}\text { Are you satisfied with the duality of education } \\
\text { delivered to you in this course? }\end{array}$ & $48 \%$ & $66,7 \%$ & $63,1 \%$ & $38 \%$ \\
\hline Is the current instruc tor qualified to teach this course? & $93 \%$ & 66,6 & $89,4 \%$ & $56 \%$ \\
\hline $\begin{array}{l}\text { Is irstructor e roo maging to ask questions and express } \\
\text { opirion in clase? }\end{array}$ & $87,1 \%$ & $89,6 \%$ & $81,5 \%$ & $76,49 \%$ \\
\hline $\begin{array}{l}\text { Is instructor stimulating your thirlsing and interest in } \\
\text { the subject? }\end{array}$ & $73,2 \%$ & $78,8 \%$ & $62,7 \%$ & $49,1 \%$ \\
\hline $\begin{array}{l}\text { Do you agree that instrue tor orgarized the ruaterial irt } \\
\text { a clear way }\end{array}$ & $89,6 \%$ & $92,3 \%$ & $83,2 \%$ & $68,9 \%$ \\
\hline
\end{tabular}


The students were asked to define the external factors affecting the course delivery. The factors as availability, non-availability of computer laboratories, flexible library rules, the presence or absence of air conditioning and other factors were rated by students according to significance. Figure 3 depicts the percentage distribution of the influence of each of these factors on the course delivery. As shown below, the highest factor of $35 \%$ resulted from library facility, another $30 \%$ was due to absence or presence of air conditioning, $25 \%$ was due to availability or non-availability of computer classes, and $10 \%$ due to other external factors. The institute took up the library issue seriously and a new modern facility is under construction. The split type aircondition makes noise and large classes suffer from improper acoustic design. The institute requires more computing facility related resources, in view of the fact that most student work requires computer use.

\section{Analysis of QFD}

\begin{tabular}{|llll}
\hline \hline & $\square$ & $\square$ \\
\hline
\end{tabular}

Figure 3. External Factors Affecting Course Delivery

The students were asked to rate the courses on the level of difficulty, 10 being the most difficult. The highest difficulty score was found for JN course with a score of 9 . The other courses scored 7 or below. The students justified their position with the following grounds: a) high expectations of the instructor; b) not providing enough tutorial hours; c) emphasis on memorization; d) simply, the student disliked the instructor.

The students suggested a set of recommendations to improve instructional pedagogy: increase the number of tutorials, restructure the exam content; increase the weight of quizzes in total grade composition; assign more experienced instructors with both teaching background and business experience.

\section{RESULTS}

The application of the TQM model at KIMEP for pedagogical development clearly implies a paradigm shift from the view of students as passive consumers of information to active participants in the achievement of educational goals [7]. This is what an empowered customer is [14]. Customer empowerment in education requires greater input from a student. However, the empowerment of a student will create a burden on an instructor who needs to be fully prepared to implement any of the numerous options made available to the student. Instructors will have to become familiar and to implement various classroom conduct techniques, starting from plain problem solving to team exercises and diversified group assignments. However, the other question arises then, are students competent to make the right choices at the time. What if the empowerment concept will eventually result in minimum course requirements and in less educational goals? Therefore, the implementation of the empowerment concept should take place only after careful revision of the quality criteria by management of KIMEP.

The House of Quality has revealed in an organized manner the needs of the students and the characteristics, which the discipline specific curriculum possesses. According to the study, only $53.5 \%$ of the students were satisfied with the quality of the courses at the target department. This number was an alarming signal to KIMEP management as a whole, meaning that if changes did not take place in the near future, KIMEP would lose its status as a leading university. The instructors of courses should work in close cooperation with the industry representatives to raise competitive graduates in their areas of specialization. The plan to implement changes may encounter resistance, but the KIMEP management should enforce a plan that is correct. Therefore, the administration should work in close cooperation with the employees, students and the industry specialist in order to achieve quality of education satisfying all parties involved in the educational process [1].

In any higher education institution, the quality of program delivered is essential in creating the prestige and brand name of the academic entity [11]. In Central Asia, KIMEP is one of the private institutions striving for excellence in everything it does. However, the target department at $\mathrm{BCB}$ along with other departments has been experiencing a high turnover rate of instructors. The instructors substantially vary in their qualifications and 
experiences. Some students, with less motivation to study and low GPA score, have welcomed the easygoing instructors, since passing the course is easy with such instructor. However, the advanced and average students have been dissatisfied with a deteriorating quality level of courses delivered and the competency of the instructor. In many instances, the goals and aims of the courses were not always well established. There was a great inconsistency of criteria in the teaching and assessment of each course. Some courses were taught in a slot categorized as lecture session with more than 100 students at a time and the same class was divided in smaller groups to be taught in tutorial classes with entirely different instructors. This strategy does not suit the business education needs at KIMEP and the interest of students were unnoticed. In technical education that approach may work; however, regular contact with the same instructor mentors a business graduate, since feedback to business students linking theory, practice and application in a business context is critical. In such a case the instructor was not fairly judged, as instances of ineffectiveness of an instructor in a large lecture class was concealed with the ability of instructors in tutorial classes or vice versa. The study suggests grouping the large class into smaller manageable sections and providing efficient course coordination with additional tutors. Additionally, there was a misfit between theoretical and practical dimensions of education plans and also the way the courses were structured. Argument has come to light that emphasis is given too much on theory and excessive number of class hours. Appropriate course coordination among multiple section courses is missing. A mechanism of curriculum revision, which allows the adaptation and updating of the contents of each subject, is lacking. With respect to providing facilities which allow teaching to take place in better conditions, important deficiencies still remain in recreational facility, resources for practical activities, space for students within academic facilities, libraries, computer resources, and little use of technological resources in teaching activities - this is in spite of great efforts with tight budgets during the past years.

\section{CONCLUSIONS}

The objective of this study was to identify and analyze the quality education in KIMEP at the BCB target department. The following issues were identified:

a) Instructor qualifications prevent students from achieving a necessary level of knowledge. The students have doubted the competency of some instructors. The pedagogical skills of the teachers need further improvement. The majority of instructors lacked real life business experience and thus ignored the importance of industry/business related knowledge and organized business/industry trips to augment business curriculum needs.

b) The course contents were not diversified to include various learning techniques and methods. The composition of the courses emphasized more on mid term and final exams, while the weight of quizzes and class work was very little in grade composition. There was a lack of tutorial sessions; the majority of sessions conducted were lectures, which entailed only theoretical knowledge. The focus group noted that some instructors intentionally omitted the problem solving parts.

c) Students identified the lack of computer labs as affecting their performance in a course and the quality of education delivered to them. The library employees also created obstacles in the study process. The non-availability of books and a constant need to print out the lecture material also affected the quality of education delivered and imposed additional financial costs on the students' tight budgets.

The problems reported by students at the target department have not appeared in one day; they have been accumulating over the semester. The high turnover rate of instructors reduced the quality of education; students cannot identify weak and strong instructors at once. The BCB student community suggested that KIMEP in the future would employ instructors with past teaching backgrounds and with business experience as well. The abilities and qualifications of instructors should be verified before employment; otherwise, the quality of education will suffer.

The course content should aim at developing various skills in students. Software usage, case studies, projects, quizzes, and team exercises should be included in the contents of courses. Specifically, the target department should not only emphasize theory but also rely more on current practice and improvement of software usage skills. The mid term exams and final exams should not be the only source of grades for the student, since the performance of the student on the exam does not always reveal factual knowledge on the subject. The free rider problem in-group assignments should also be eliminated.

KIMEP should increase the number of computer labs in the future, since almost all assignments of the 
instructors were related to word processing or Excel computations; therefore, every single student of KIMEP needs flexible access to computer resources. The library resources should be expanded in the near future, since insufficient resources create difficulty for students, especially during the examination period when there is only one book per 20 students. The computer lab assistants should be more communicative and nice to students, since their rude attitude at times is also creating a tense atmosphere in the computer labs.

For KIMEP to maintain a leading position and leadership in higher education, it should implement changes to its existing system. Unless changes are planned, the customer satisfaction, which is only $53.5 \%$ now, will decrease even further. The best students of KIMEP may eventually leave this institution due to lack of quality-based education. The HoQ has identified the needs of students. The QFD survey revealed the current problems faced by students. Hence, management ought to respond to the VOC effectively to resolve the issues. Finally, let's use a vivid example of a frog in the context of organizational obsolesces as described in Rao et al., 1995. If one puts a frog in boiling water, the frog will immediately realize that water is hot and dangerous, and jump out. However, if the frog is in cold water, and the water temperature rises till it boils, the frog dies, for it cannot recognize the transition to danger. Much is the same for organizations. Often they don't implement any changes until they are dying and simply continue the day-to-day operations without recognizing the changing competitive environment or opportunities until it's too late. In the case of the frog, the dissatisfaction from boiling water made it jump and therefore seek change, while in the educational institution, the disappointment can stem from a variety of sources. The stakeholder may be dissatisfied with the quality of graduates. Dissatisfaction itself is an undesirable outcome, but it can also be positive and stimulate a desire for change in an organization where change may be resisted.

\section{REFERENCES}

1. Athiyaman, A. (1997). Linking student satisfaction and service quality perceptions: the case of university education. European Journal of Marketing, 31(7), 528-540.

2. Bowen, H.R. (1980). The Costs of Higher Education: How Much do Colleges and Universities Spend per Student and How Much Should they Spend? Jossey-Bass: San Frano, CA.

3. Benjamin, C.O. \& Pattanapanchai, S. (1993), A QFD framework for developing engineering laboratories. International Journal of Applied Engineering Education, 9(5), 422-9.

4. Chappell, R.T. (1994), Can TQM in public education survive without co-production?. Quality Progress, 27(7), 41-44.

5. Chen, C.-L. \& Bullington, S.F. (1993). Development of a strategic research plan for an academic department through the use of quality function deployment. Computers \& Industrial Engineering, 25(1-4), 49-52.

6. Clayton, M. (1993). Treading the quality path: a progress report from Aston University, in Pipe, D.W. (Ed.), Quality Management in Universities, Australian Government Publishing Service, Canberra, 450-453.

7. Ermer, D.S. (1995). Using QFD becomes an educational experience for students and faculty. Quality Progress, May, 131-136.

8. Hwarng, H. B. \& Cynthia, T. (2001). Translating customers' voices into operations requirements A QFD application in higher education. International Journal of Quality \& Reliability Management, 18(2), 195-225.

9. Jaraiedi, M. \& Ritz, D. (1994). Total quality management applied to engineering education, Quality Assurance in Education, 2(1), 32-40.

10. Juran, J.M. (1982). Juran on Quality by Design. The New Steps for Planning Quality into Goods and Service, Free Press: New York,NY.

11. Zhumadil M, Alimbayeva D, \& Baiuzakova M. (2005). Project Report: TQM Application in Higher Education, OMIS, BCB, KIMEP.

12. Sirvanci, M. B. (2004). Critical issues for TQM implementation in higher education. The TQM Magazine, 16(6), 382-386.

13. Rao, A., Carr. R. L., Dambolene, I., Kopp, R, J., Martin, J., Rafii, F., \& Schlesinger, P. F. (1996). Total Quality Management - A cross functional perspective, JW: NY, USA.

14. Sakthivel, P.B., Rajendran, G., \& Raju R. (2005). TQM implementation and students' satisfaction of academic performance. The TQM Magazine, 17), (6), 573-589.

15. Durlabhji, S. G. \& Fusilier, M. R. (1999). The empowered classroom: Applying TQM to college teaching. Managing Service Quality, 9(2), 110-115.

16. Toombs, W. (1973). Productivity: Burden of success, ERIC/Higher Education Research Report (2), American Association for Higher Education: Washington D.C. 